Polymer Journal, Vol. 38, No. 11, pp. 1173-1181 (2006)

(C) 2006 The Society of Polymer Science, Japan

\title{
Helicity Induction in $N$-[(4-Butyl)triphenylmethyl]- methacrylamide Sequence via Radical Copolymerization with Chiral Monomers
}

\author{
A. K. M. Fakhrul Azam, ${ }^{1}$ Masami Kamigaito, ${ }^{1}$ Masashi Tsuji, ${ }^{2}$ and Yoshio OKAmoto ${ }^{2, \dagger}$ \\ ${ }^{1}$ Department of Applied Chemistry, Graduate School of Engineering, Nagoya University, \\ Furo-cho, Chikusa-ku, Nagoya 464-8603, Japan \\ ${ }^{2}$ EcoTopia Science Institute, Nagoya University, Furo-cho, Chikusa-ku, Nagoya 464-8603, Japan
}

(Received August 8, 2006; Accepted August 28, 2006; Published October 11, 2006)

\begin{abstract}
The radical copolymerization of $N$-[(4-butyl)triphenylmethyl]methacrylamide (BuTrMAM) with optically active monomers, such as $N$-[(R)-(+)-1-(1-naphthyl)ethyl]methacrylamide, $N$-[(S)-(-)-1-(1-naphthyl)ethyl]methacrylamide, $N$ - $((S)-(+)-1$-cyclohexylethyl)methacrylamide, $N$ - $((R)-(-)$-1-cyclohexylethyl)methacrylamide, $N$ ((S)-(-)-1-benzylpyrrolidin-3-yl)methacrylamide, and $N$-( $(R)-(+)-1$-benzylpyrrolidin-3-yl)methacrylamide, was carried out. The optical activity of the obtained copolymers significantly depended on the monomer contents. When the chiral monomer content was low in the copolymers, the chiral monomeric units were effective in inducing an excess of the one-handed helix consisting of BuTrMAM monomeric sequences. The helicity induction was most effectively attained using $N$-[1-(1-naphthyl)ethyl]methacrylamide at low temperature. The chiroptical properties and chiral recognition ability of the obtained copolymers were studied in detail. [doi:10.1295/polymj.PJ2006091]

KEY WORDS Helix-Sense-Selective / Copolymerization / Optically Active Polymer / Helicity / Chiral Recognition Ability / HPLC /
\end{abstract}

The synthesis of helical polymers is an important field in macromolecular science as they are used in a wide variety of potential applications based on the chiral structure. ${ }^{1-6}$ Helical structures are often found in naturally occurring macromolecules, which show characteristic features based on the structure. Although a helical conformation is also found for stereoregular synthetic polymers in the solid state, it often disappears in solution because of fast conformational dynamics. However, there are several classes of polymers that can maintain the helical conformation even in solution. ${ }^{7}$

Triphenylmethyl methacrylate (TrMA) produces a highly isotactic, optically active polymer through asymmetric anionic polymerization using the complexes of organolithium compounds and chiral ligands. $^{7-9}$ The optical activity of poly(TrMA) is mainly based on a one-handed helical conformation of the main chain, which is maintained by steric repulsion between the bulky side groups. The direction of the helix is controlled by the chirality of the ligands of the initiator complexes. Optically active phenyl-2pyridyl-o-tolylmethyl methacrylate (PPyoTMA), ${ }^{10,11}$ a TrMA analogue with a chiral ester group, also produces an optically active helical polymer by anionic polymerization. ${ }^{12}$ However, during this polymerization, the helix sense is controlled by the chirality of the ester group rather than by that of the initiator. The radical copolymerization of PPyoTMA with
TrMA also produced optically active, isotactic polymers, in which the PPyoTMA residues effectively induced an excess of a single-handed helix consisting of TrMA monomeric sequences. ${ }^{13}$

Lewis acids, such as rare earth metal triflates, significantly increase the isotactic specificity during the radical polymerization of acrylamide and methacrylamide derivatives. ${ }^{14-18}$ However, these polymerization systems have been unsuccessful in producing optically active polymers. On the other hand, we recently studied the radical polymerization of bulky methacrylamides, $N$-(triphenylmethyl)methacrylamide (TrMAM) and its derivatives, $N$ - $\left[\left(4,4^{\prime}\right.\right.$-dibutyl)triphenylmethyl]methacrylamide (DBuTrMAM) ${ }^{19}$ and $\quad N$-[(4-butyl)triphenylmethyl]methacrylamide $(\mathrm{BuTrMAM}){ }^{20}$ All the polymers obtained in the presence of (+)- and (-)-menthol were highly isotactic and optically active. The optical rotation and CD intensities of these polymers were lower than that of the anionically obtained one-handed helical poly(TrMA), indicating that the one-handedness of the poly(methacrylamide)s may not be very high. Copolymers prepared from achiral and chiral vinyl monomers sometimes show disproportionately high optical activities. ${ }^{21}$ Thus, higher one-handed helical sequences of the bulky methacrylamides may be formed through the copolymerization with a chiral methacrylamide. In the present study, the radical copolymerization of BuTrMAM with six optically active methacrylamides,

${ }^{\dagger}$ To whom correspondence should be addressed (Tel: +81-52-789-4600, Fax: +81-52-789-3188, E-mail: okamoto@apchem.nagoya-u.ac.jp). 


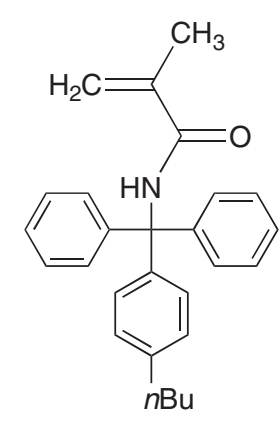

BuTrMAM

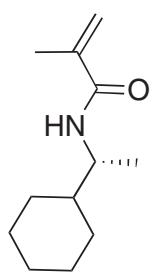

(-)-CHEMAM

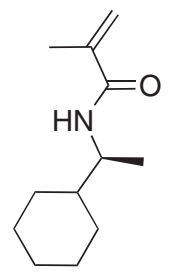

(+)-CHEMAM



(-)-BPMAM

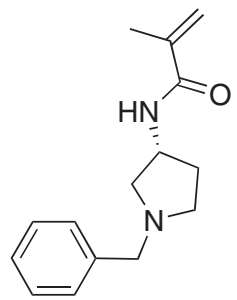

(+)-BPMAM

(-)-NEMAM

Scheme 1.

i.e., $\quad N$-[(R)-(+)-1-(1-naphthyl)ethyl]methacrylamide $((+)-N E M A M), N-[(S)-(-)-1-(1-$ naphthyl)ethyl]methacrylamide $((-)$-NEMAM $), N-((S)-(+)-1$-cyclohexylethyl)methacrylamide $((+)$-CHEMAM $), N-((R)-(-)$ 1-cyclohexylethyl)methacrylamide ((-)-CHEMAM), $N$ - $((S)$-(-)-1-benzylpyrrolidin-3-yl)methacrylamide $((-)$-BPMAM), and $N-((R)-(+)-1$-benzylpyrrolidin-3yl)methacrylamide $((+)$-BPMAM), were carried out (Scheme 1). The optical activities of the obtained copolymers were significantly different from those expected from the chiral monomer contents, indicating that the prevailing one-handed helical sequences of BuTrMAM monomeric units may be induced by the chiral monomer. The $\mathrm{CD}$ data of the copolymers also supported this hypothesis.

\section{EXPERIMENTAL}

\section{Materials}

Methacryloyl chloride was distilled before use. Triethylamine was dried over $\mathrm{KOH}$ and distilled. Anhydrous solvents, including dichloromethane, chloroform, tetrahydrofuran (THF), methanol, and toluene were purchased from Kanto Chemical, and used as received. 2,2'-Azobisisobutylonitrile (AIBN) was recrystallized from methanol. Chiral amines, $(R)-(-)$ 1-cyclohexylethylamine (Aldrich; >98\%), $(S)-(+)-1-$ cyclohexylethylamine (Aldrich; >98\%), $(R)-(+)-1-$ (1-naphthyl)ethylamine (Aldrich; >99\%), (S)-(-)-1(1-naphthyl)ethylamine (Aldrich; >99\%), $(R)-(-)-1-$ benzyl-3-aminopyrrolidine (Aldrich; >95\%), $(S)-(+)-$ 1-benzyl-3-aminopyrrolidine (Aldrich; >97\%) were used as commercially obtained.

\section{Monomer Synthesis}

BuTrMAM was synthesized by the previously reported procedure. ${ }^{20}$ Optically active monomers were prepared by the reaction of the corresponding amines and methacryloyl chloride in the presence of triethylamine in chloroform according to the previously reported procedure. ${ }^{22}$ The monomers were identified by NMR and elemental analysis. BuTrMAM, (+)CHEMAM, (-)-CHEMAM, (+)-NEMAM, and (-)NEMAM are known monomers, and (+)-BPMAM and (-)-BPMAM are new monomers to the best of our knowledge.

$N-[(R)-(+)-1-(1-$ naphthyl)ethyl]methacrylamide ((+)NEMAM). Yield 70\%. mp: $112.1-112.8^{\circ} \mathrm{C}$. (mp: $\left.112^{\circ} \mathrm{C}^{23}\right)[\alpha]_{\mathrm{D}}{ }^{25}+40.9^{\circ} \cdot[\alpha]_{365^{25}}+221.3^{\circ}$.

$N-[(S)-(-)-1-(1-$ naphthyl)ethyl]methacrylamide ((-)NEMAM). Yield 73\%. mp: $112.4-112.9^{\circ} \mathrm{C} .[\alpha]_{\mathrm{D}}{ }^{25}$ $-41.1^{\circ} \cdot[\alpha]_{365^{25}}-222.4^{\circ}$.

$N-((S)-(+)-1$-cyclohexylethyl)methacrylamide ((+)CHEMAM). Yield 56\%. mp: $93.4-93.8^{\circ} \mathrm{C} .[\alpha]_{\mathrm{D}}{ }^{25}$ $+16.0^{\circ} .[\alpha]_{365}{ }^{25}+40.1^{\circ}$.

$N-((R)-(-)-1$-cyclohexylethyl)methacrylamide ((-)CHEMAM). Yield 61\%. mp: 93.1-93.6 ${ }^{\circ} \mathrm{C}$. (mp: $\left.92{ }^{\circ} \mathrm{C}^{23}\right)[\alpha]_{\mathrm{D}}{ }^{25}-16.1^{\circ} .[\alpha]_{365^{25}}-40.3^{\circ}$.

$N$-((S)-(-)-1-benzylpyrrolidin-3-yl)methacrylamide $((-)-B P M A M)$. Yield: 80\%. mp: $77.7-78.6^{\circ} \mathrm{C} .[\alpha]_{\mathrm{D}}{ }^{25}$ $-14.1^{\circ} .[\alpha]_{365^{25}}-48.1^{\circ} .{ }^{1} \mathrm{H}$ NMR $\left(\mathrm{CDCl}_{3}\right): \delta 1.65(\mathrm{~m}$, $1 \mathrm{H}$, pyrrolidine), $1.94\left(\mathrm{~s}, 3 \mathrm{H}\right.$, allyl $\left.\mathrm{CH}_{3}\right), 2.31(\mathrm{~m}, 2 \mathrm{H}$, 
pyrrolidine), $2.60(\mathrm{~m}, 2 \mathrm{H}$, pyrrolidine $), 2.87(\mathrm{~m}, 1 \mathrm{H}$, pyrrolidine), 3.61 (s, $2 \mathrm{H}$, benzylene $\left.\mathrm{CH}_{2}\right), 4.50(\mathrm{~m}, 1 \mathrm{H}$, pyrrolidine $-\mathrm{CH}(\mathrm{CH}-\mathrm{NH})), 5.3(\mathrm{~s}, 1 \mathrm{H}$, vinyl), 5.65 (s, $1 \mathrm{H}$, vinyl), $6.15(\mathrm{~s}, 1 \mathrm{H},-\mathrm{NH}), 7.25-7.35(\mathrm{~m}, 5 \mathrm{H}$, aromatic) ppm. ${ }^{13} \mathrm{C}$ NMR $\left(\mathrm{CDCl}_{3}, 300 \mathrm{MHz}\right): \delta 167.82$, 140.25 , 138.84, 128.93, 128.48, 127.26, 119.46, 60.99, 60.33, 52.94, 49.09, 32.88, 19.02; Elemental analysis; Found: C, $73.75 \%$; H, 8.17\%; N, $11.28 \%$. Calcd for $\mathrm{C}_{15} \mathrm{H}_{20} \mathrm{~N}_{2} \mathrm{O}: \mathrm{C}, 73.74 \% ; \mathrm{H}, 8.25 \%$; N, $11.47 \%$.

$N-((R)-(+)-1$-benzylpyrrolidin-3-yl)methacrylamide ((+)-BPMAM). Yield: $72 \% . \mathrm{mp}: \quad 77.5-78.5^{\circ} \mathrm{C}$. $[\alpha]_{\mathrm{D}}{ }^{25}+14.2^{\circ} \cdot[\alpha]_{365}{ }^{25}+48.3^{\circ} .{ }^{1} \mathrm{H}$ NMR $\left(\mathrm{CDCl}_{3}\right): \delta$ 1.65 (m, $1 \mathrm{H}$, pyrrolidine), 1.94 (s, $3 \mathrm{H}$, allyl $\left.\mathrm{CH}_{3}\right), 2.31$ ( $\mathrm{m}, 2 \mathrm{H}$, pyrrolidine), $2.60(\mathrm{~m}, 2 \mathrm{H}$, pyrrolidine), 2.87 (m, $1 \mathrm{H}$, pyrrolidine), $3.61\left(\mathrm{~s}, 2 \mathrm{H}\right.$, benzylene $\left.\mathrm{CH}_{2}\right)$, $4.50(\mathrm{~m}, 1 \mathrm{H}$, pyrrolidine $-\mathrm{CH}(\mathrm{CH}-\mathrm{NH})), 5.3(\mathrm{~s}, 1 \mathrm{H}$, vinyl), $5.65(\mathrm{~s}, 1 \mathrm{H}$, vinyl), $6.15(\mathrm{~s}, 1 \mathrm{H},-\mathrm{NH}), 7.25-$ 7.35 (m, 5H, aromatic) ppm. ${ }^{13} \mathrm{C} \mathrm{NMR}\left(\mathrm{CDCl}_{3}, 300\right.$ $\mathrm{MHz}): \delta$ 167.82, 140.25, 138.84, 128.93, 128.48, 127.26, 119.46, 60.99, 60.33, 52.94, 49.09, 32.88, 19.02; Elemental analysis; Found: C, 73.74\%; H, $8.23 \% ; \mathrm{N}, 11.38 \%$. Calcd for $\mathrm{C}_{15} \mathrm{H}_{20} \mathrm{~N}_{2} \mathrm{O}: \mathrm{C}, 73.74 \%$; $\mathrm{H}, 8.25 \%$; N, $11.47 \%$.

\section{Polymerization Procedure}

The radical polymerization was carried out under dry nitrogen in a glass tube equipped with a threeway stopcock using AIBN as an initiator at $60^{\circ} \mathrm{C}$. The polymerization using AIBN at $0^{\circ} \mathrm{C}$ was initiated by the irradiation of UV light (400-W high-pressure mercury lamp). Liquid materials were transferred to the glass tube using syringes and the solid monomer using a funnel having a nitrogen gas inlet tube. As neat BuTrMAM is very reactive, it was preserved as a hexane solution. The BuTrMAM $(0.1 \mathrm{~g}, 0.26 \mathrm{mmol})$ in hexane solution was placed in the glass tube and then hexane was evaporated under a reduced pressure at low temperature $\left(0^{\circ} \mathrm{C}\right)$ and a polymerization solvent $(0.52 \mathrm{~mL})$ was added in it. The chiral monomers were added in the polymerization system according to the molar ratio with BuTrMAM. The solution was maintained at prescribed temperature for $24 \mathrm{~h}$. The polymerization was terminated by cooling the reaction mixture at $-78^{\circ} \mathrm{C}$. The reaction mixture was dissolved in chloroform $(5 \mathrm{~mL})$, and was poured into a large amount of methanol. The precipitated polymers were isolated using a centrifuge, washed several times with methanol to remove the unreacted monomers, and dried at $60^{\circ} \mathrm{C}$ for $10 \mathrm{~h}$.

\section{Chiral Adsorption}

The optically active polymers synthesized by the copolymerization of BuTrMAM and (+)- or (-)NEMAM $(96 / 4, \mathrm{~mol} / \mathrm{mol})$ at $0{ }^{\circ} \mathrm{C}$ were used to evaluate their chiral recognition ability. The copolymer
(20 mg) was placed in a $0.3 \mathrm{~mL}$ screw-capped glass vial. A solution of a racemic compound in methanol, hexane, or isooctane $\left(200 \mu \mathrm{L}\right.$, conc. $\left.=0.25 \mathrm{~g} \mathrm{~L}^{-1}\right)$ was added to the polymer. The mixture was allowed to stand for $12 \mathrm{~h}$ in a tightly capped container. The e.e. of the analyte in the sample solution was analyzed using the supernatant solution $(10 \mu \mathrm{L})$ by an HPLC system equipped with a JASCO UV-970 UV detector, a JASCO OR-990 polarimeter, and a Daicel Chiralcel OD column $(25 \mathrm{~cm} \times 0.46 \mathrm{~cm}$ (i.d. $))$.

The separation factor $(\alpha)$ was determined by the following equation where the superscripts ' $\mathrm{f}$ ' and 'ads' denote the free (in solution part) and adsorbed (on the polymer), respectively: ${ }^{24}$

$$
\begin{aligned}
& \alpha=\frac{\text { major antipode } \left.^{\mathrm{f}}(\%)\right) /\left(\text { minor antipode }^{\mathrm{f}}(\%)\right)}{\left(\text { major antipode }^{\text {ads }}(\%)\right) /\left(\text { minor }^{\text {antipode }}{ }^{\text {ads }}(\%)\right)}
\end{aligned}
$$

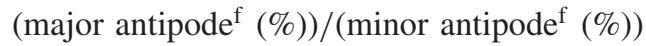

$$
\begin{aligned}
& =\overline{\left(50-\text { major antipode }^{\mathrm{f}}(\%)\right) /\left(50-\text { minor }_{\text {antipode }} \mathrm{f}(\%)\right)}
\end{aligned}
$$

where

$$
\begin{aligned}
\text { major antipode }^{\mathrm{f}}(\%)= & (100-\text { adsorption yield }(\%)) \\
& \times\left(100+\text { e.e. } .^{\mathrm{f}} \mid\right) / 2 \times 1 / 100 \\
\text { minor antipode }^{\mathrm{f}}(\%)= & (100-\text { adsorption yield }(\%)) \\
& \times\left(100-\mid \text { e.e. }{ }^{\mathrm{f}} \mid\right) / 2 \times 1 / 100
\end{aligned}
$$

\section{Measurements}

The ${ }^{1} \mathrm{H}$ NMR spectra were recorded on a Varian Gemini 2000 spectrometer $\left(400 \mathrm{MHz}\right.$ for $\left.{ }^{1} \mathrm{H}\right)$. The number average molecular weight $\left(M_{\mathrm{n}}\right)$ and polydispersity $\left(M_{\mathrm{w}} / M_{\mathrm{n}}\right)$ of the obtained polymers were determined by size-exclusion chromatography (SEC) calibrated using standard polystyrenes on a JASCO PU980 pump equipped with a JASCO RI-930 detector using TSKgel $\mathrm{GMH}_{\mathrm{HR}}-\mathrm{H}$ and $\mathrm{G} 3000_{\mathrm{HR}}$ columns connected in series (eluent THF; temperature $40^{\circ} \mathrm{C}$ ). The optical rotation was measured in either THF or chloroform at $25^{\circ} \mathrm{C}$ temperature with a JASCO P-1030 polarimeter. The circular dichroism (CD) spectra were measured with a JASCO J-720L spectrometer.

\section{RESULTS AND DISCUSSION}

\section{Radical Copolymerization of BuTrMAM with (+)- or (-)-BPMAM}

It is well known that several copolymers prepared from achiral and chiral vinyl monomers show a high optical activity due to the contribution of the achiral monomer units. The radical copolymerization of PPyoTMA with TrMA gave optically active, isotactic polymers; the chiral phenyl-2-pyridyl-o-tolylmethyl group was effective in inducing an excess of a single-handed helix consisting of TrMA monomeric sequences. ${ }^{18}$ 
A. K. M. F. AZAM et al.

Table I. Radical copolymerization of BuTrMAM with (-)-BPMAM in toluene ${ }^{\text {a }}$

\begin{tabular}{rccccccccr}
\hline Run & $\begin{array}{c}\text { BuTrMAM } \\
\begin{array}{c}(-)-\text {-BPMAM } \\
(\mathrm{mol} / \mathrm{mol})\end{array}\end{array}$ & $\begin{array}{c}\text { Temp. } \\
\left({ }^{\circ} \mathrm{C}\right)\end{array}$ & Initiator & $\begin{array}{c}\text { Yield }^{\mathrm{b}} \\
(\%)\end{array}$ & $\begin{array}{c}(-) \text {-BPMAM in } \\
\text { copolymer }^{\mathrm{f}} \\
(\mathrm{mol} \%)\end{array}$ & $\begin{array}{c}M_{\mathrm{n}}{ }^{\mathrm{d}} \\
\times 10^{4}\end{array}$ & $M_{\mathrm{w}} / M_{\mathrm{n}} \mathrm{d}^{\mathrm{d}}$ & $\begin{array}{c}{[\alpha]_{\mathrm{D}}{ }^{\mathrm{e}}} \\
(\mathrm{deg})\end{array}$ & $\begin{array}{c}{[\alpha]_{365}{ }^{\mathrm{e}}} \\
(\mathrm{deg})\end{array}$ \\
\hline 1 & $99 / 1$ & 60 & AIBN & 85 & 1.0 & 4.31 & 29.12 & +2.3 & +6.5 \\
2 & $98 / 2$ & 60 & AIBN & 83 & 2.0 & 3.86 & 16.15 & +2.9 & +7.8 \\
3 & $97 / 3$ & 60 & AIBN & 81 & 2.6 & 3.43 & 12.95 & +4.2 & +12.3 \\
4 & $96 / 4$ & 60 & AIBN & 80 & 3.4 & 3.15 & 9.30 & +0.6 & +1.8 \\
5 & $95 / 5$ & 60 & AIBN & 82 & 4.5 & 2.71 & 9.08 & +0.4 & +1.1 \\
\hline 6 & $90 / 10$ & 60 & AIBN & 73 & 10.1 & 1.98 & 5.06 & -1.5 & -4.5 \\
7 & $80 / 20$ & 60 & AIBN & 67 & 21.1 & 1.66 & 3.29 & -3.9 & -11.8 \\
8 & $70 / 30$ & 60 & AIBN & 63 & 31.2 & 1.43 & 2.54 & -6.8 & -19.7 \\
9 & $60 / 40$ & 60 & AIBN & $58^{\mathrm{c}}$ & 40.3 & 1.37 & 1.95 & -11.2 & -33.7 \\
10 & $50 / 50$ & 60 & AIBN & $53^{\mathrm{c}}$ & 51.0 & 1.08 & 1.64 & -16.9 & -51.6 \\
\hline 11 & $98 / 2$ & 0 & AIBN & 70 & 1.9 & 4.13 & 11.51 & +2.8 & +7.6 \\
12 & $97 / 3$ & 0 & AIBN & 67 & 2.5 & 3.95 & 10.23 & +4.1 & +12.1 \\
\hline 13 & $0 / 100^{\mathrm{g}}$ & 60 & AIBN & 66 & - & 0.42 & 1.98 & -19.7 & -61.9 \\
\hline
\end{tabular}

${ }^{\mathrm{a}}$ Initiator $=\mathrm{AIBN}(0.02 \mathrm{M})$, time $=24 \mathrm{~h},[\mathrm{BuTrMAM}]_{0}+[\mathrm{BPMAM}]_{0}=0.5 \mathrm{~mol} / \mathrm{L} .{ }^{\mathrm{b}} \mathrm{MeOH}$-insoluble part. ${ }^{\mathrm{c}} \mathrm{Hexane}$ insoluble part. ${ }^{\mathrm{d}}$ Determined by SEC in THF (PMMA standard) at $40{ }^{\circ} \mathrm{C}$. ${ }^{\mathrm{e}} \mathrm{In}$ THF at $25^{\circ} \mathrm{C}$, conc. $=5 \mathrm{mg} / \mathrm{mL}$, cell length $=2 \mathrm{~cm}$. ${ }^{\mathrm{f}}$ Calculated by ${ }^{1} \mathrm{H}$ NMR. ${ }^{\mathrm{g}}$ Homopolymerization of (-)-BPMAM.

As the isotactic BuTrMAM chain produced by radical polymerization can form a helical conformation, ${ }^{20}$ the copolymerization of BuTrMAM and (-)-BPMAM was carried out to obtain a copolymer with a high onehanded helicity induced by the optically active monomer. These results are shown in Table I. All the copolymers were soluble in THF and chloroform. The copolymer compositions were very close to the corresponding feed monomer composition, suggesting that the copolymerization mostly proceeded in a random manner. When a small amount of (-)-BPMAM (runs 1 to 5, Table I) was copolymerized with BuTrMAM, dextrorotatory (positive) polymers were obtained. The sign of the rotation is opposite that of the homopolymer and copolymers with the higher (-)-BPMAM contents. This suggests that the rotation of the polymer may be based on the helical conformation of the main chain. The CD pattern of the obtained copolymers having a small amount of chiral BPMAM (Figure 1) is similar to that of the helical BuTrMAM homopolymers obtained in the presence of $(+)$ - and (-)-menthol. ${ }^{21}$ This result also supports the one-handed helical conformation of the BuTrMAM sequence in the copolymer. The $\mathrm{CD}$ intensities of the copolymers are much lower than that of the BuTrMAM homopolymers obtained in the presence of (+)- and (-)menthol. This indicates that the helicity induction by the BPMAMs is not very high. The optical activities of the copolymers obtained at 0 and $60{ }^{\circ} \mathrm{C}$ were similar, indicating that the polymerization temperature cannot significantly influence the helicity induction. The optical activity and the CD intensity of the copolymers were the highest for the copolymerization system using 3\% (-)-BPMAM (Figure 1). When the

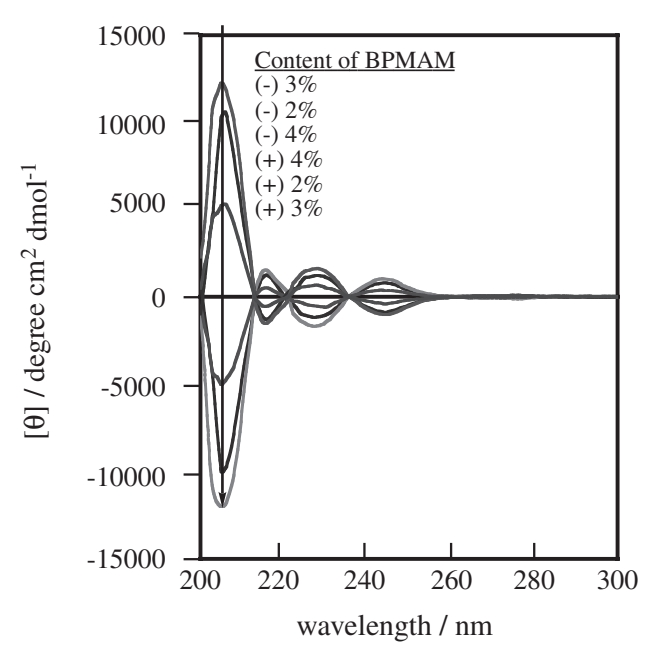

Figure 1. CD spectra of the copolymers of BuTrMAM with (+)- and (-)-BPMAM ( $2 \%$ to $4 \%$ ) (THF, r.t.).

amount of the feed (-)-BPMAM in the copolymerization system is very low (1 3\%), the obtained polymer may contain high molecular weight BuTrMAM homopolymer and also copolymer of low molecular weight, which will result in broad molecular weight distribution. Once (-)-BPMAM is incorporated into a BuTrMAM sequence, the polymerization may be retarded giving a low molecular weight copolymer, because homopolymerization of (-)-BPMAM gives a very low molecular weight polymer. The molecular weights of the copolymers were in between the range of the two homopolymers. When (-)-BPMAM content exceeded $10 \%$, the optical rotation of the copolymers became levorotatory or negative. The optical activity of these copolymers may be mainly due to 
the chiral side group of the (-)-BPMAM units because the optical rotation of the (-)-BPMAM homopolymer (run 13, Table I) is negative. Before the formation of the helical structure of the BuTrMAM sequences, the BuTrMAM units neighboring a (-)BPMAM residue seem to contribute exhibiting the negative rotation, because the 1:1 copolymer (run 10, Table I) has a specific rotation rather similar to that of the (-)-BPMAM homopolymer (run 13, Table I). However, as the BuTrMAM sequence gets longer, it starts to form a helical structure with a positive rotation, and its contribution will become a maximum at about $3 \%$ of the (-)-BPMAM content, because the induced helical structure may not be maintained for a very long sequence.

When (+)-BPMAM was used in the copolymerization system, the copolymers showed an optical activity almost exactly opposite to that of the copolymers with (-)-BPMAM (Figure 2). The optical activity of the copolymers was not significantly changed by the polymerization solvents, such as THF and toluene.

\section{Radical Copolymerization of BuTrMAM with (+)- or (-)-CHEMAM}

The radical copolymerization of BuTrMAM with $(+)$ - or (-)-CHEMAM was carried out in toluene at $60^{\circ} \mathrm{C}$ (Table II). The copolymer compositions were similar, particularly for low CHEMAM contents, to the feed monomer contents. During the radical copolymerization of BuTrMAM with (-)-CHEMAM, the optical rotation of the copolymers increased to ca. $4 \%$ (-)-CHEMAM content in the copolymer,



Figure 2. Plot of optical rotation $v$ s the content of BPMAM in the copolymers.

and the further addition of this monomer resulted in a gradual increase in the optical rotation in the negative direction (Figure 3) and a gradual decrease in the molecular weight (Table II). When the content of the chiral monomer was low, the copolymer exhibited an optical rotation opposite to that of the feed (-)-CHEMAM, suggesting that the BuTrMAM sequence may form a prevailing one-handed helical chain. The CD patterns also support this suggestion (Figure 4). When the chiral monomer content was low, the CD spectra of the copolymers resemble that of the optically active BuTrMAM homopolymer obtained in menthol, although the CD intensities of the copolymers are lower. These results are similar to those for the previous copolymers consisting of (-)-BPMAM.

For the copolymerization of BuTrMAM with (+)-

Table II. Radical copolymerization of BuTrMAM with (+)- and (-)-CHEMAM in toluene ${ }^{\mathrm{a}}$

\begin{tabular}{|c|c|c|c|c|c|c|c|c|c|}
\hline Run & $\begin{array}{c}\frac{\text { BuTrMAM }}{\text { CHEMAM }} \\
(\mathrm{mol} / \mathrm{mol})\end{array}$ & $\begin{array}{c}\text { Temp. } \\
\left({ }^{\circ} \mathrm{C}\right)\end{array}$ & Initiator & $\begin{array}{c}\text { Yield }^{\mathrm{b}} \\
(\%)\end{array}$ & $\begin{array}{c}\text { CHEMAM } \\
\text { in copolymerf } \\
(\mathrm{mol} \%)\end{array}$ & $\begin{array}{c}M_{\mathrm{n}}{ }^{\mathrm{c}} \\
\times 10^{4}\end{array}$ & $M_{\mathrm{w}} / M_{\mathrm{n}}^{\mathrm{c}}$ & $\begin{array}{l}{[\alpha]_{\mathrm{D}}{ }^{\mathrm{d}}} \\
(\mathrm{deg})\end{array}$ & $\begin{array}{r}{[\alpha]_{365}} \\
(\mathrm{deg})\end{array}$ \\
\hline 1 & $97 / 3(+)$ & 60 & AIBN & 100 & 3.0 & 9.6 & 5.1 & -3.8 & -11.5 \\
\hline 2 & $96 / 4(+)$ & 60 & AIBN & 98 & 4.0 & 8.5 & 6.3 & -4.1 & -12.5 \\
\hline 3 & $95 / 5(+)$ & 60 & AIBN & 98 & 5.0 & 8.1 & 9.0 & -2.8 & -8.3 \\
\hline 4 & $94 / 6(+)$ & 60 & AIBN & 94 & 6.0 & 4.6 & 5.9 & -2.6 & -7.7 \\
\hline 5 & $97 / 3(-)$ & 60 & AIBN & 97 & 3.0 & 9.4 & 5.3 & +4.0 & +12.1 \\
\hline 6 & $96 / 4(-)$ & 60 & AIBN & 97 & 4.0 & 8.6 & 6.5 & +4.9 & +14.8 \\
\hline 7 & $95 / 5(-)$ & 60 & AIBN & 98 & 5.0 & 8.1 & 7.9 & +2.9 & +9.0 \\
\hline 8 & $94 / 6(-)$ & 60 & AIBN & 94 & 6.0 & 4.9 & 12.7 & +2.5 & +7.8 \\
\hline 9 & $90 / 10(-)$ & 60 & AIBN & 95 & 7.8 & 5.0 & 9.1 & +1.9 & +5.7 \\
\hline 10 & $80 / 20(-)$ & 60 & AIBN & 99 & 20.0 & 4.5 & 3.1 & +0.6 & +1.7 \\
\hline 11 & $70 / 30(-)$ & 60 & AIBN & 98 & 28.7 & 3.7 & 2.7 & -0.7 & -2.2 \\
\hline 12 & $60 / 40(-)$ & 60 & AIBN & 97 & 38.6 & 2.2 & 1.7 & -5.1 & -15.3 \\
\hline 13 & $50 / 50(-)$ & 60 & AIBN & 79 & 43.2 & 1.7 & 1.6 & -8.5 & -25.5 \\
\hline $14^{\mathrm{e}}$ & $0 / 100^{\mathrm{g}}(-)$ & 60 & AIBN & 61 & - & 1.6 & 1.3 & -18.8 & -57.1 \\
\hline
\end{tabular}

${ }^{\mathrm{a}}$ Initiator $=\operatorname{AIBN}(0.02 \mathrm{M})$, time $=24 \mathrm{~h},[\text { BuTrMAM }]_{0}+\left[\mathrm{CHEMAM}_{0}=0.5 \mathrm{~mol} / \mathrm{L} .{ }^{\mathrm{b}} \mathrm{MeOH}-\right.$ insoluble part. ${ }^{\mathrm{c}}$ Determined by SEC in THF (PMMA standard) at $40{ }^{\circ} \mathrm{C}$. ${ }^{\mathrm{d}} \mathrm{In}$ THF at $25^{\circ} \mathrm{C}$, conc. $=5 \mathrm{mg} / \mathrm{mL}$, cell length $=2 \mathrm{~cm}$. ${ }^{\mathrm{e}}[\mathrm{M}]=$ $1.0 \mathrm{M} .{ }^{\mathrm{f}}$ Calculated by ${ }^{1} \mathrm{H}$ NMR. ${ }^{\mathrm{g}}$ Homopolymerization of (-)-CHEMAM. 
or (-)-CHEMAM, the optical activity of the copolymers was not noticeably influenced by the polymerization temperature as well as in the previous polymerization system.

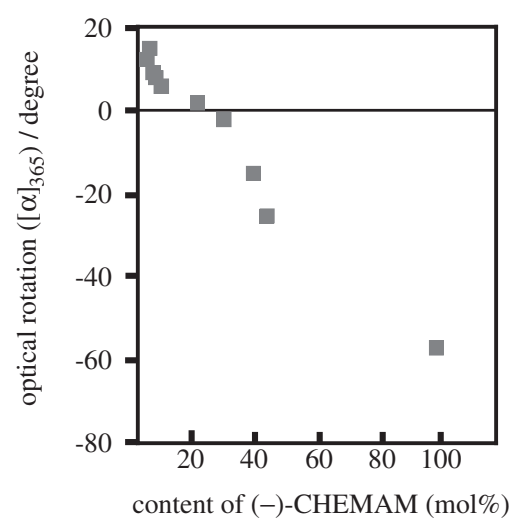

Figure 3. Plot of optical rotation $v s$ the content of (-)CHEMAM in the copolymers (Table II).

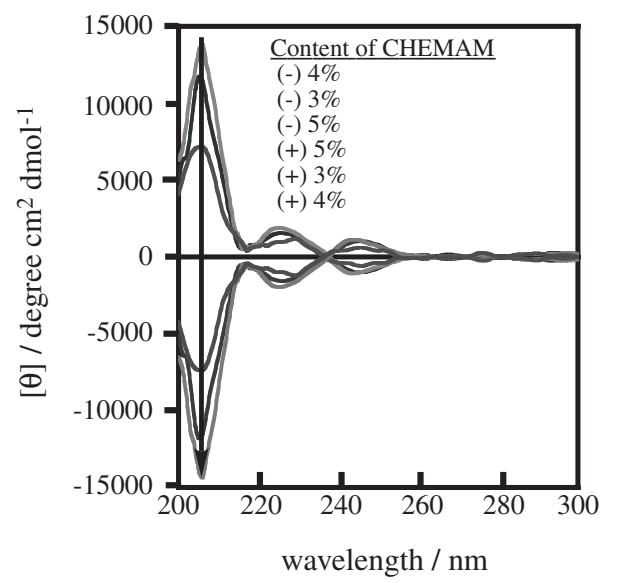

Figure 4. CD spectra of the copolymers of BuTrMAM with (+)- and (-)-CHEMAM (3\% to 5\%) (THF, r.t.).
Radical Copolymerization of BuTrMAM with (+)- or (-)-NEMAM

The radical copolymerization of BuTrMAM with (+)-NEMAM was also carried out in toluene at $60{ }^{\circ} \mathrm{C}$ (Table III). The optical rotation of the copolymers gradually increased with an increase in the chiral monomer content up to $20 \%$, and a further increase of the chiral monomer resulted in an increase in the optical rotation in the opposite direction and finally arrived at the optical rotation of the (+)-NEMAM homopolymer, which was opposite that of the monomer. The CD spectra due to the helical structure of the BuTrMAM sequences were clearly observed when the (+)-NEMAM content in the copolymers was low (Figure 5). In the copolymers, the BuTrMAM units neighboring (+)-NEMAM seem to contribute to the positive rotation as well as the helical structure of the BuTrMAM sequences induced by (+)-NEMAM. Due to these synergy effects and probably higher helical induction, the copolymer appears to exhibit

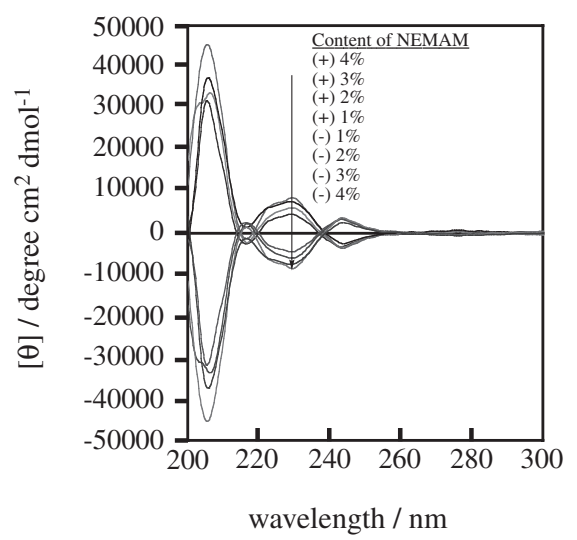

Figure 5. CD spectra of the copolymers of BuTrMAM with (+)- and (-)-NEMAM ( $1 \%$ to $4 \%$ ) obtained at $60{ }^{\circ} \mathrm{C}$ in toluene (THF, r.t.).

Table III. Radical copolymerization of BuTrMAM with (+)-NEMAM in toluene ${ }^{\mathrm{a}}$

\begin{tabular}{|c|c|c|c|c|c|c|c|c|}
\hline Run &  & $\begin{array}{c}\text { Temp. } \\
\left({ }^{\circ} \mathrm{C}\right)\end{array}$ & $\begin{array}{c}\text { Yield }^{\text {b }} \\
(\%)\end{array}$ & $\begin{array}{c}(+)-\text { NEMAM in } \\
\text { copolymer } \\
(\mathrm{mol} \%)\end{array}$ & $\begin{array}{l}M_{\mathrm{n}}{ }^{\mathrm{c}} \\
\times 10^{4}\end{array}$ & $M_{\mathrm{w}} / M_{\mathrm{n}}^{\mathrm{c}}$ & $\begin{array}{c}{[\alpha]_{D}{ }^{d}} \\
(\operatorname{deg})\end{array}$ & $\begin{array}{c}{[\alpha]_{365}{ }^{\mathrm{d}}} \\
(\mathrm{deg})\end{array}$ \\
\hline 1 & $99 / 1$ & 60 & 84 & 1.0 & 5.46 & 4.16 & +5.1 & +18.7 \\
\hline 2 & $98 / 2$ & 60 & 81 & 2.0 & 3.31 & 6.33 & +6.6 & +26.8 \\
\hline 3 & $97 / 3$ & 60 & 80 & 3.0 & 2.94 & 6.70 & +8.8 & +36.0 \\
\hline 4 & $96 / 4$ & 60 & 79 & 4.0 & 2.33 & 6.70 & +13.4 & +50.3 \\
\hline 5 & $90 / 10$ & 60 & 72 & 10.5 & 4.23 & 2.10 & +15.5 & +59.6 \\
\hline 6 & $80 / 20$ & 60 & 85 & 21.0 & 1.32 & 4.84 & +29.2 & +113.8 \\
\hline 7 & $70 / 30$ & 60 & 86 & 31.2 & 1.29 & 3.50 & +26.3 & +101.2 \\
\hline 8 & $60 / 40$ & 60 & 80 & 41.3 & 1.12 & 2.90 & +12.5 & +47.5 \\
\hline 9 & $50 / 50$ & 60 & 76 & 52.0 & 1.02 & 2.52 & +0.4 & +1.4 \\
\hline 10 & $0 / 100^{f}$ & 60 & 74 & - & 1.00 & 2.35 & -24.0 & -43.2 \\
\hline
\end{tabular}

${ }^{\mathrm{a}}$ Initiator $=\mathrm{AIBN}(0.02 \mathrm{M})$, time $=24 \mathrm{~h},[\mathrm{BuTrMAM}]_{0}+[\mathrm{NEMAM}]_{0}=0.5 \mathrm{~mol} / \mathrm{L} .{ }^{\mathrm{b}} \mathrm{MeOH}$-insoluble part. ${ }^{\mathrm{c}}$ Determined by SEC in THF (PMMA standard) at $40{ }^{\circ} \mathrm{C}$. ${ }^{\mathrm{d}} \mathrm{In} \mathrm{THF}$ at $25^{\circ} \mathrm{C}$, conc. $=5 \mathrm{mg} / \mathrm{mL}$, cell length $=2 \mathrm{~cm}$. ${ }^{\mathrm{e}} \mathrm{Calculated}$ by ${ }^{1} \mathrm{H}$ NMR. ${ }^{\mathrm{f}}$ Homopolymerization of (+)-NEMAM. 
Table IV. Radical copolymerization of BuTrMAM with (-)-NEMAM at 0 and $60{ }^{\circ} \mathrm{C}$ in toluene ${ }^{\mathrm{a}}$

\begin{tabular}{|c|c|c|c|c|c|c|c|c|}
\hline Run & 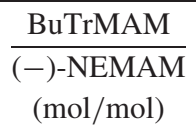 & $\begin{array}{c}\text { Temp. } \\
\left({ }^{\circ} \mathrm{C}\right)\end{array}$ & $\begin{array}{c}\text { Yield }^{\mathrm{b}} \\
(\%)\end{array}$ & $\begin{array}{c}(-) \text {-NEMAM in } \\
\text { copolymer }^{\mathrm{e}} \\
(\mathrm{mol} \%)\end{array}$ & $\begin{array}{l}M_{\mathrm{n}}{ }^{\mathrm{c}} \\
\times 10^{4}\end{array}$ & $M_{\mathrm{w}} / M_{\mathrm{n}}^{\mathrm{c}}$ & $\begin{array}{l}{[\alpha]_{D}{ }^{d}} \\
(\mathrm{deg})\end{array}$ & $\begin{array}{c}{[\alpha]_{365}{ }^{\mathrm{d}}} \\
(\mathrm{deg})\end{array}$ \\
\hline 1 & $96 / 4$ & $0 / \mathrm{UV}$ & 59 & 4.3 & 2.53 & 3.08 & -44.8 & -169.3 \\
\hline 2 & $96 / 4$ & 60 & 78 & 4.0 & 3.02 & 5.20 & -13.9 & -49.3 \\
\hline 3 & $80 / 20$ & $0 / \mathrm{UV}$ & 34 & 21.4 & 1.26 & 2.59 & -41.2 & -156.0 \\
\hline 4 & $80 / 20$ & 60 & 76 & 21.0 & 1.62 & 4.04 & -33.2 & -127.7 \\
\hline 5 & $70 / 30$ & $0 / \mathrm{UV}$ & 25 & 31.8 & 1.21 & 2.56 & -32.3 & -148.7 \\
\hline 6 & $70 / 30$ & 60 & 82 & 31.5 & 1.32 & 3.61 & -28.4 & -107.8 \\
\hline 7 & $0 / 100^{f}$ & $0 / \mathrm{UV}$ & 17 & - & 1.11 & 1.98 & +27.3 & +53.5 \\
\hline 8 & $0 / 100^{f}$ & 60 & 76 & - & 1.13 & 2.04 & +23.5 & +42.8 \\
\hline 9 & $100 / 0^{\mathrm{g}}$ & $0 / \mathrm{UV}$ & 81 & - & 30.0 & 5.30 & -9.7 & -29.3 \\
\hline
\end{tabular}

${ }^{\mathrm{a}}$ Initiator $=\mathrm{AIBN}(0.02 \mathrm{M})$, time $=24 \mathrm{~h},[\mathrm{BuTrMAM}]_{0}+[\mathrm{NEMAM}]_{0}=0.5 \mathrm{~mol} / \mathrm{L} .{ }^{\mathrm{b}} \mathrm{MeOH}-$ insoluble part. ${ }^{\mathrm{c}}$ Determined by SEC in THF (PMMA standard) at $40{ }^{\circ} \mathrm{C}$. ${ }^{\mathrm{d}}$ In THF at $25{ }^{\circ} \mathrm{C}$, conc. $=5 \mathrm{mg} / \mathrm{mL}$, cell length $=2 \mathrm{~cm}$. ${ }^{\mathrm{e}} \mathrm{Calculated}$ by ${ }^{1} \mathrm{H}$ NMR. ${ }^{\mathrm{f}}$ Homopolymerization of (-)-NEMAM. ${ }^{\mathrm{g}}$ Homopolymerization of BuTrMAM in (+)-menthol $(0.45 \mathrm{~g})$.

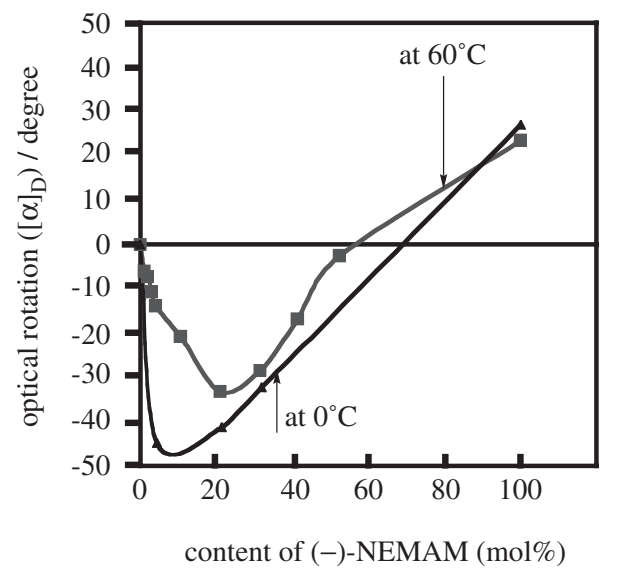

Figure 6. Plots of (-)-NEMAM content $v s$ optical rotation $\left([\alpha]_{\mathrm{D}}\right)$ of poly[BuTrMAM-co-NEMAM]s obtained at 0 and $60^{\circ} \mathrm{C}$ (Table III and Table IV).

higher optical activities.

The optical activities of the copolymers of BuTrMAM with (+)- and (-)-NEMAM are opposite of each other as expected.

\section{Temperature Dependence of Helical Induction in Poly(BuTrMAM-co-NEMAM)}

Although no significant change in the optical activity was observed for the copolymers of BuTrMAM with the optically active BPMAM and CHEMAM obtained at different temperatures, the copolymer of BuTrMAM with the optically active (-)-NEMAM obtained at $0{ }^{\circ} \mathrm{C}$ exhibited a higher optical activity than the copolymer prepared at $60^{\circ} \mathrm{C}$ (Table IV). The temperature more significantly influenced the optical activity when the (-)-NEMAM content was low (Figure 6). The CD pattern of the copolymer (run 1, Table IV) containing $4.3 \%$ of the chiral monomer residue resembles that of the homopolymer (run 9) of BuTrMAM obtained in the presence of

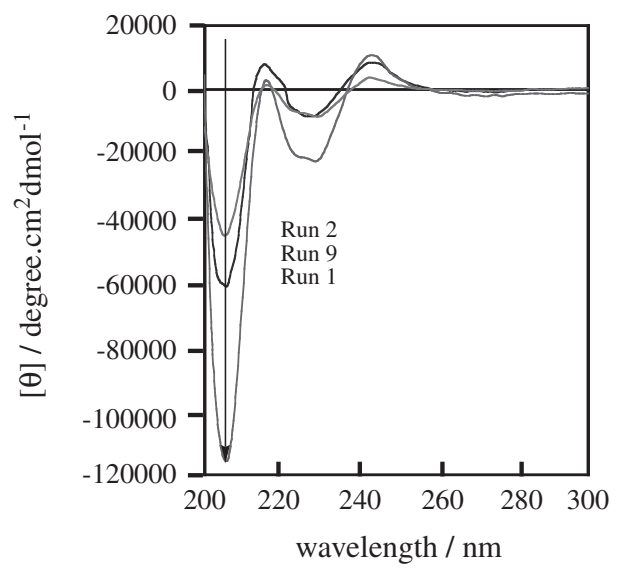

Figure 7. $\mathrm{CD}$ spectra of copolymers with lower content of (-)-NEMAM (4\%) and the homopolymer of BuTrMAM (Table IV) (THF, r.t.).

(+)-menthol (Figure 7), and its intensity is greater than that of the homopolymer. The helicity induction by the optically active NEMAM seems to be more effectively attained when the polymerization temperature is low.

\section{Chiral Recognition by Optically Active Poly(BuTr- MAM-co-NEMAM)}

The chiral recognition ability of the optically active poly(BuTrMAM-co-NEMAM) obtained by the copolymerization of BuTrMAM with (+)- and (-)$\operatorname{NEMAM}(96 / 4, \mathrm{~mol} / \mathrm{mol})$ at $0{ }^{\circ} \mathrm{C}$ was evaluated by the chiral adsorption method ${ }^{24}$ using trans-stilbene oxide and Tröger's base as the racemates (Table V). Each racemate was adsorbed by $c a .30 \sim 50 \%$ on the optically active poly(BuTrMAM-co-NEMAM) in methanol, hexane, and isooctane. The enantiomeric excess (e.e.) of the free solutes in a supernatant solution was estimated by HPLC using a chiral column. Although the e.e. was very low, the excess enantiom- 
Table V. Chiral recognition ability of the copolymers [BuTrMAM (96\%) with (+)- or (-)-NEMAM $(4 \%)$ at $\left.0^{\circ} \mathrm{C}\right]$ at r.t. ${ }^{a}$

\begin{tabular}{|c|c|c|c|c|c|}
\hline $\begin{array}{c}\text { Copolymer } \\
\text { (monomers) } \\
(\mathrm{mol} / \mathrm{mol})\end{array}$ & Solvent & $\begin{array}{l}\text { Racemate } \\
\text { (Analyte) }\end{array}$ & $\begin{array}{l}\text { Adsorbed } \\
\text { analyte } \\
(\%)\end{array}$ & $\begin{array}{l}\text { E.E. of free analyte } \\
\text { in supernatant } \\
\text { solution }(\%)\end{array}$ & $\begin{array}{l}\text { Separation } \\
\text { factor }(\alpha)^{\mathrm{c}}\end{array}$ \\
\hline \multirow{6}{*}{$\begin{array}{c}\frac{\text { BuTrMAM }}{(-)-\text { NEMAM }} \\
(96 / 4)\end{array}$} & \multirow[t]{2}{*}{$\mathrm{MeOH}$} & Tröger's base & 45 & $(+) 2.1$ & 1.10 \\
\hline & & Stilbene oxide & 38 & $(-) 2.7$ & 1.14 \\
\hline & \multirow[t]{2}{*}{ Hexane } & Tröger's base & 41 & (+) 1.6 & 1.09 \\
\hline & & Stilbene oxide & 34 & $(-) 1.7$ & 1.11 \\
\hline & \multirow[t]{2}{*}{ Isooctane } & Tröger's base & 46 & (+) 1.6 & 1.08 \\
\hline & & Stilbene oxide & 51 & $(-) 1.3$ & 1.06 \\
\hline \multirow{6}{*}{$\begin{array}{c}\text { BuTrMAM } \\
(+)-\text { NEMAM } \\
(96 / 4)\end{array}$} & \multirow[t]{2}{*}{$\mathrm{MeOH}$} & Tröger's base & 49 & (-) 2.9 & 1.15 \\
\hline & & Stilbene oxide & 37 & (+) 1.9 & 1.11 \\
\hline & \multirow[t]{2}{*}{ Hexane } & Tröger's base & 32 & $(-) 1.1$ & 1.07 \\
\hline & & Stilbene oxide & 48 & (+) 2.2 & 1.10 \\
\hline & \multirow[t]{2}{*}{ Isooctane } & Tröger's base & 42 & (-) 1.0 & 1.06 \\
\hline & & Stilbene oxide & 50 & $(+) 1.2$ & 1.08 \\
\hline
\end{tabular}

${ }^{\mathrm{a} C}$ Copolymer $=20 \mathrm{mg}$; racemate analyte $0.05 \mathrm{mg}(200 \mu \mathrm{L}$ portion from a $0.25 \mathrm{mg} / \mathrm{mL}$ solution in methanol. ${ }^{\mathrm{b}}$ Determined by HPLC analysis of supernatant solution using a Chiralcel OD column, hexane/IPA (95/5), flow rate; $0.5 \mathrm{~mL} / \mathrm{min}$. ${ }^{\mathrm{c}}$ Calculated according to $\alpha=\left(\mathrm{F}_{\text {minor }}(\%) / \mathrm{F}_{\text {major }}(\%)\right) /\left(\mathrm{A}_{\text {major }}(\%) / \mathrm{A}_{\text {minor }}(\%)\right)$.

ers were reversed depending on the chirality of the copolymers. This suggests that the data are sufficiently reliable. The low enantioselectivity of the poly(BuTrMAM-co-NEMAM)s compared to that of the one-handed helical poly(TrMA) may be due to the existence of the butyl group. It is known that the existence of a methyl group on the helical diphenyl-2pyridylmethyl methacrylate polymers reduces the chiral recognition ability of the polymer..$^{25}$ The low one-handedness or the lack of a propeller structure of the trityl group in the copolymers may also cause this lower enantioselectivity.

\section{CONCLUSIONS}

The helix-sense-selective radical copolymerization was examined using BuTrMAM as a helix forming unit and three optically active monomers, BPMAM, CHEMAM, and NEMAM, as the helix inducing unit. The CD patterns of the copolymers containing low contents of the chiral monomers resemble that of the helical homopolymer of BuTrMAM obtained in the presence of (+)- and (-)-menthol, suggesting that the optically active monomeric units can induce a single-handed helical conformation of the BuTrMAM sequence via copolymerization. The helical induction by the chiral (-)-NEMAM was very effective at low temperature, and the obtained copolymer exhibits a higher optical activity than that of the homopolymer of BuTrMAM obtained in the optically active menthol. The chiral recognition ability of the obtained copolymers was much lower compared to that of the one-handed helical poly(TrMA).
Acknowledgment. This study was supported by a Grant-in-Aid for Scientific Research (C), No. 17550116, by the Ministry of Education, Culture, Sports, Science, and Technology, Japan.

\section{REFERENCES}

1. T. Nakano and Y. Okamoto, Chem. Rev., 101, 4013 (2001).

2. T. Nakano, J. Chromatogr., A, 906, 205 (2001).

3. C. Yamamoto and Y. Okamoto, Bull. Chem. Soc. Jpn., 77, 227 (2004).

4. G. Wulff, Angew. Chem., Int. Ed., 28, 21 (1989).

5. J. J. L. M. Cornelissen, A. E. Rowan, R. J. M. Nolte, and N. A. J. M. Sommerdijk, Chem. Rev., 101, 4039 (2001).

6. M. Reggelin, M. Schultz, and M. Holbach, Angew. Chem., Int. Ed., 41, 1614 (2002).

7. Y. Okamoto and T. Nakano, Chem. Rev., 94, 349 (1994).

8. Y. Okamoto, K. Suzuki, K. Ohta, K. Hatada, and H. Yuki, J. Am. Chem. Soc., 101, 4763 (1979).

9. T. Nakano, Y. Okamoto, and K. Hatada, J. Am. Chem. Soc., 114, 1318 (1992).

10. E. Yashima, Y. Okamoto, and K. Hatada, Polym. J., 19, 728 (1987).

11. E. Yashima, Y. Okamoto, and K. Hatada, Macromolecules, 21, 854 (1988).

12. Y. Okamoto, E. Yashima, and K. Hatada, J. Polym. Sci., Part C: Polym. Lett., 25, 297 (1987).

13. Y. Okamoto, M. Nishikawa, T. Nakano, E. Yashima, and K. Hatada, Macromolecules, 28, 5135 (1995).

14. Y. Isobe, D. Fujioka, S. Habaue, and Y. Okamoto, J. Am. Chem. Soc., 123, 7180 (2001).

15. S. Habaue, Y. Isobe, and Y. Okamoto, Tetrahedron, 58, 8205 (2002).

16. Y. Isobe, Y. Suito, S. Habaue, and Y. Okamoto, J. Polym. Sci., Part A: Polym. Chem., 41, 1027 (2003). 
17. B. Ray, Y. Isobe, S. Habaue, M. Kamigaito, and Y. Okamoto, Polym. J., 36, 728 (2004).

18. B. Ray, Y. Okamoto, M. Kamigaito, M. Sawamoto, K. Seno, S. Kanaoka, and S. Aoshima, Polym. J., 37, 234 (2005).

19. N. Hoshikawa, Y. Hotta, and Y. Okamoto, J. Am. Chem. Soc., 125, 12380 (2003).

20. A. K. M. F. Azam, M. Kamigaito, and Y. Okamoto, Polym. $J$. , in press.

21. C. Carlini, F. Ciardelli, and P. Pino, Makromol. Chem., 119,
244 (1968).

22. B. Yamada, T. Tanaka, S. Mori, and T. Otsu, J. Macromol. Sci., Part A: Pure Appl. Chem., 23, 697 (1986).

23. G. Blaschke and F. Donow, Chem. Ber, 108, 2792 (1975).

24. T. Nakano, Y. Satoh, and Y. Okamoto, Polym. J., 30, 635 (1998).

25. H. Mohri, Y. Okamoto, and K. Hatada, Polym. J., 21, 719 (1989). 